IRA-International Journal of Education \& Multidisciplinary Studies

ISSN 2455-2526; Vol.06, Issue 03 (2017)

Pg. no. 260-265

Institute of Research Advances

https://research-advances.org/index.php/IJEMS

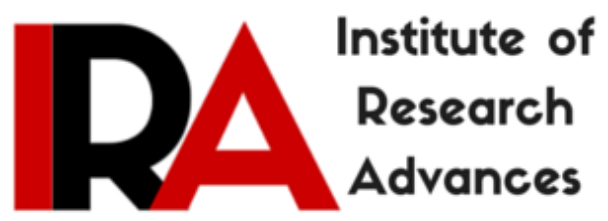

\title{
Managing Performance in the Higher Education System
}

\author{
Nisha Solanki \\ Assistant Professor, IINTM, GGSIPU, Delhi, India.
}

Type of Review: Peer Reviewed.

DOI: http://dx.doi.org/10.21013/jems.v6.n3.p6

\section{How to cite this paper:}

Solanki, N. (2017). Managing Performance in the Higher Education System. IRA International Journal of Education and Multidisciplinary Studies (ISSN 2455-2526), 6(3), 260-265. doi:http://dx.doi.org/10.21013/jems.v6.n3.p6

(C) Institute of Research Advances

\section{(cc) BY-No}

This work is licensed under a Creative Commons Attribution-Non Commercial 4.0 International License subject to proper citation to the publication source of the work.

Disclaimer: The scholarly papers as reviewed and published by the Institute of Research Advances (IRA) are the views and opinions of their respective authors and are not the views or opinions of the IRA. The IRA disclaims of any harm or loss caused due to the published content to any party. 
Managing Performance of employees plays a focal role in any organisation. The current study identifies the need of an efficient and biased free Performance management system in the Higher Education Institutions. Performance Management plays a vital role in motivating the employees to bring efficiency in the work place. Although institutions and the management are aware of its relevance and the positive outcomes, yet it remains more of a concept which is actually not implemented correctly. With the helping of existing literature and data sources, this paper aims to highlight the importance of Performance management systems. Also suggesting how to overcome the various hindrances that are been faced in the institutions.

Keywords: Performance management (PM); effectiveness; procedure; higher educational Institutes

\section{Introduction:}

Performance Management Systems are always of imperative concern of any organization/ institution while managing its human resource. Although, higher education institutions depends upon both teaching and non-teaching staff working in it, yet majority of responsibility comes upon faculties who are the source of student's knowledge, learning and development. Therefore this need of faculties' performance demands a systematic, fair, genuine, smart, effective, appropriate, and motivating Performance Management System.Due to this reason, Performance Management has become the key instrument used by policy- makers to improve the education system.

\section{Problems Faced by Higher Education System regarding Performance Management System:}

Performance management is the basic requirement for the success of any organization as it is directly proportional to the morale, motivation and dedication of its employees. More the quality and transparency anorganization brings in their performance management system, more the employees will be happy. In higher education systems, the main USP are the faculties and the quality of faculties an institution is having is actually creating a difference between the institution and the competitors. Hiring the quality faculty can be easy task but to manage and retain those quality faculties demands more efforts. The faculties can be retained by implementing the fair functions in the institution and one of the critical systems to implement is Performance Management System (PMS). Performance management in education sector is comparatively more critical because a complex combination of qualitative and quantitative factors need to be considered. Today the education sector is facing so many issues and problems due to faulty performance appraisal system. In most of the institutes, the PMS is more linked with pay and salaries and taken as an important input for the incremental decisions. For this reason the faculties feel more pressure to achieve targets for saving the job and to expect more increment. While achieving those quantitative targets somewhere faculties used to ignore their personal development and not contribute to the research part of the sector. Another major challenge is to get biasfree appraisal from the superiors and from students also. No formal training is given to the appraisers to elaborate how to go for appraisal. Some of the appraisers are biased, some are not skilled to give feedback and some of the appraisers are not having appropriate skills to analyse and evaluate. These problems lead to faulty appraisal of the faculties. In some institutions faculties have misconception that better relations with superiors will be entertained with good feedback irrespective of the performance due to which faculties used to sit with superiors and waste their quality time to maintain relations with students by engaging them in irrelevant talks. These irrelevant talks during the class brings inaccuracy and biased feedback from the insincere students for those faculties who does not entertain useless talks during the class and focus more to teaching and knowledge sharing and transferring. Not only teaching plays a role in institute but other roles like mentoring, counselling, disturbance handling, etc also have their importance and make the role of a faculty complete. Institutes are not giving more weightage to these supportive and augmented roles of a faculty which is resulting into low morale of the faculties to act like a real teacher for the students. The biggest problem institutes are facing now a days in tough competition is increasing standards of 
qualification which is creating a tough hurdle in the way of those capable faculties who are more experienced but unfortunately not having latest qualification standard and concerned certification. To manage overconfident degree holders is a real challenge for the PMS of the institution. The PMS must be designed like it gives real, accurate, unbiased, genuine and up to date feedback about the faculties and help to manage the faculties who are misusing the qualification degree and the formal designation by not performing upto the desired and expected level. PMS should be designed for the up gradation and developmental aspect of the faculties in education sector and must be free from the problems which contribute to the failure of the institute. Government and education authority should also develop and mandate some standards to check the performance of the faculties.

\section{Role of Performance Management System in Education Sector:}

Performance Management is the basics for any type of organization. This is needed to accomplish the specific goals of the organization and to know where exactly it want to reach in the near future and long term future.With the advancement of technology in every field, the education sector has also started implementing new technologies and solutions for better functioning and management of the education institutes.

Longenecker (1999) found that there are many reasons, why an organization needs a formal performance management system. It is needed to take smart decisions regarding salary increases, promotions, demotions, terminations, and transfers.

PMS can assess and suggest the required improvements in the productivity of faculties. It also helps management to forecast the upcoming challenges smartly and beyond that it also helps organization to upgrade its faculties as per the requirements. Effective PMS always acts like a tool for capability analysis and capacity building for the faculties. Moreover, as PMS brings effectiveness in the most productive unit of institution, i.e faculties, it makes the future of nation better which depends upon the quality of education youth is getting.

\section{Purpose of the Study:}

Performance Management is an on-going communication process, undertaken in a partnership between an employee and his/ her immediate supervisor and involves establishing clear expectations and understandings (Bacal 1999). The objective of PMS entail the meaningful contribution towards service delivery and addressing the Batho Pele (people first) principle in dealing with community challenges in Educational Transformation. The main objective of PMS is to align and clarify the organizational, departmental, team and individual, efforts and expectations thereby ensuring that energies are directed at achieving the strategic goals.

- This research study aims towards finding out the various problems higher institutions are facing to implement an effective Performance Management System.

- Also aims to analyse various PMS applied in the different institutions and universities.

- This research is also aiming to throw some light to the fundamental pitfalls and suggestions to avoid those loop holes for making the PMS effective and efficient so that the performance can be rewarded accurately and appropriately.

\section{Literature Review:}

Professor Pankaj Jalote, I.I.T. Kanpur (2005) executed a research on Indian universities to find the role of R\&D in PMS in HES. He used secondary data from different universities and articles and draws some findings: lack of R\&D activity in education institute implies degradation in the quality of education. Only the places that have kept some R\&D activity going are still able to provide a high quality education like IITs, IISc, Delhi school of economics, BITS, IIMs, FMS, etc. Teachers needs to be motivated to do more R\&D in HES. Currently, HES in India have no regular appraisal of teachers based on which incentives for doing good $R \& D$ ( and disincentives for not contributing much on the $\mathrm{R} \& \mathrm{D}$ front) are given. He suggested that the criteria for appraisal should attach suitable weight to the 
R\&D performance, and should be clearly articulated. The key aspect of this scheme is that it requires a performance appraisal every year of all the teachers, and this appraisal separates the performers from the average and under performers. This will also ensure that appraisals are indeed done in time and seriously. This will slowly lead to other systems being developed to support and promote R\&D.

M.L.E. Mapesela and Francois Strydom (2006) conducted a research at University of the Free State, Bloemfontein, South Africa to explore the status of performance management systems already in place in South African higher education institutions. They followed a case study approach to understanding the nature of performance management system (PMS) in higher education system (HES) in South Africa. Case study approach was followed by primary data analysis by adopting snowball sampling with the use of teachers, support staff, institutional experts and management as sampling unit. The findings of this research revealed that the PMS in all the institutions were having many more similarities than the differences. The PMS in HES is linked variably. Some institutes linked with pay, some linked with development and promotion and some linked with the teacher's insights. Teachers appreciate flexible PMS and balanced perspective on academic workload. The major problem found in PMS is the lack of greater prioritization. Teachers and staff highlighted the need for clear communication of strategic objectives in the institution. It was observed that typical business approaches to PMS would not work in HES. Therefore existing performance management models and approaches need to be adapted to the needs and vision of higher education institutions and followed by the gradual introduction of the system that allows for a process of institutional transformation and systematic adjustments. The development of these complex systems needs to draw on the expertise of management, support and teachers in order for it to be successful.

Forrest W. Flaniken, College of Education, University of Central Florida, Orlando, FL (2009), conducted an exploratory study to determine if Christian Colleges and Universities in the United States are using Performance Management System with their staff and faculties as a management tool and to understand the frequency of use, the benefits obtained and challenges incurred in using PMS. He took 108 institutions that are US members of Council for Christian colleges and Universities (CCCU) as the population for the study. The format chosen to conduct this study was a selfadministered online questionnaire consisting of closed end questions. The HR Directors at each CCCU institutions were taken as sample and were asked to complete questionnaire for their institutions. A pilot study was undertaken to finalize the questionnaire and a set of 33 questions was finalized. Cronbach's Alpha was used to measure the internal consistency and reliability of questionnaire. The whole data was analyzed using Descriptive statistics including Percentile rank and mean score for each of the variables. The findings of the study includes: $84.4 \%$ of the institutions were using PMS for their faculties and staff. 90.8\% institutions of CCCU used annual appraisals. PMS is described as managerial instrument for goal setting and performance planning with employees, encouraging interactions concerning employee growth and development, as a basis for wage and salary changes. The major challenges in making PMS successful were found as, supervisory resistance to give ratings, especially negative ratings, supervisor's personal values and bias with organizational PMS, varying standards and ratings also unfair sometimes from supervisor to supervisor. The major challenge in using PMS is lack of leadership support for PMS. The researcher suggested automated PMS to increase ease of use and to save time and efforts. PMS must be consistent and time bound throughout the organization. Training should be given to supervisors to make PMS more effective.

Juliet Namuddu, Education of Makerere University, Uganda, 2010, carried out a descriptive research through cross sectional survey to examine the relationship between the PMS on faculty performance in aga khan schools in Kampala from 2002- 2008 through the focus on the schools evaluation, the faculty based evaluations and communications channel that are important in PMS. Research was inclined to establish relationship between faculty based evaluation on faculty performance and to establish relationship between the schools evaluation criteria and faculty performance. Both primary as well as secondary schools were taken as population for the research. The population, research and especially the time period of the study was chosen to sort out the problem of drastically declining faculty performance leading to poor student performance which was 
evidenced in the school's record. The study concentrated on two schools which employed more than 200 faculties and 10 administers who were concerned with the management and implementation of the staff appraisal system. A sample of 97 was chosen out of the target population. To get this sample, the sampling technique stratified and purposive was used. Both primary as well as well as secondary data was used. Primary data was collected from faculties, coordinators, heads and administrators. She used self-administered questionnaire consisting of closed end questions. The hypothesis teacher based evaluation have a positive relationship with faculty performance was accepted. Important to note was that more emphasis was lacking on "peer" evaluation and student based evaluation that can help the faculty further assess the extent to which he/ she has performed. Another hypothesis that the school's evaluation criteria have a positive relationship with faculty performance was also accepted. The researcher concluded that the evaluation criteria lacked more detail, organization, and emphasis of individual activities such as; actual teaching, public/ employee relations, and extra activities.

Dr. Muhammad Tahir Khan Farooqi, ASSISTANT Professor, University of Education, Lahore, Pakistan, Dr. Hafiz Muhammad Ather Khan, Assistant Professor, Department of Educational Training, The Islamia University of Bahawalpur, Muhammad Arsalan, Govt. Degree College, Hujra Shah Muqeem, Okara, Pakistan, 2012, analyzed a problem of falling performance of faculties in public sector in comparision to private sector and intended a descriptive research aiming at comparing the PMS of public sector and private sector institutions. The survey technique was used to conduct the descriptive study. The target population of the study was all the public and private secondary schools situated in the jurisdiction of sahiwal division. As okara district was accessible for the researchers, they took a sample of 100 schools in the jurisdiction of okara district (50 public and 50 private schools). Random sampling technique was used to get the sample. Data was collected from heads of selected schools. A survey questionnaire namely Performance Appraisal Questionnaire (PAQ) was developed on three point likert scale. PAQ was piloted upon 30 heads of institutes both public and private. The reliability coefficient was calculated as 0.75 . The researchers analyzed the data by using SPSS Version 19. Statistical techniques viz. independent sample t- test and pearson $r$ correlation were applied to analyze the data. The result of the study shows that no difference exists between public schools and private schools and there is no significant relationship is found between faculty performance and appraisal. Public sector schools are having more facilities than private sector schools but the private sector schools produce much better results. It is also concluded that the better performance is due to better supervision and monitoring. It was recommended that by applying foolproof and effective appraisal system in public sector schools can produce the excellent results.

SayantaniGhosh, Assistant Professor, Dr. B.C Roy Engineering College, Durgapur, West Bengal and Niladri Das, Assistant Professor, Department of Management Studies, Indian Schools of Mines, Dhanbad, Jharkhand, 2013, has explored the data in the exploratory study through literature review. This has been conducted to study the PMS of faculties in higher education system. The study is based upon secondary data and the data is collected through books, journals, internet, articles, etc. It has been found that PMS is more focused on individual accomplishment in India whereas in international scenario, PMS is more inclined towards organizational success. In India, PMS is more characterized with high power distance but power distance is very low in other countries. In national context, motivational needs are oriented towards affiliation and socialization but in international context, same are more oriented towards self-actualization needs. In Indian education sector, 360 degree appraisal, confidential report, graphic rating scale, BARS, MBO etc are used whereas Balance Scorecard, SMART performance pyramid, EFQM, Performance measurement matrix, performance Prism etc are used in international educational institutions. PMS in India has lesser trust than PMS in international context as in International Context PMS is handled very systematically, transparently, and fairly. Educational institutions in India struggle because many employees doubt whether a performance management system can actually identify superior performance, they also question that whether these systems actually reward good performance. These emotional responses affect employee's perception of how robust that is and whether it can distribute rewards fairly and effectively. 


\section{Findings \& Conclusion:}

On the basis of personal observation and discussion and also after going through the literature review and other secondary data, some of the important findings are listed below:

- In some institutions, faculties are forced to prove quantitative results like pass percentage, average score of students, etc but the major part research work is being ignored which results into monotonous teaching without updations.

- The rigid PMS is being implemented which cannot bring effectiveness in faculties as faculties are human beings and vary individually.

- Superiors are also found without particular training to give feedback and to analyse the performance which spoils the overall rating and ranking of faculties.

- The participation of faculties is not found in PMS which decrease the morale and sense of belongingness among faculties and somewhere affects the satisfaction level.

- PMS is only focussed towards the performance of faculties in institution but the benefit of development of faculties is little bit ignored.

\section{Suggestions:}

- The PMS must be transparent and the participation of faculties must be invited so that faculties do not take the feedback fake and in genuine.

- Flexibility in PMS can bring more effectiveness as individuals very with each other and needs also vary. When PMS is linked with right need satisfaction, it will add more quality.

- The PMS should not be teaching specific for the faculties. It should also include some research concept as research is the demand of the time.

- The development areas finding and providing the developmental opportunities can also be taken as a part of PMS.

- The superiors must also be trained for giving feedback and analysing the data so that the result can be quote accurately.

\section{References:}

1. Comparison of Performance Appraisal System in Public \& Private Sectors Higher Secondary Schools, Dr. Muhammad Tahir Khan Farooqi, ASSISTANT Professor, University of Education, Lahore, Pakistan, Dr. Hafiz Muhammad Ather Khan, Assistant Professor, Department of Educational Training, The Islamia University of Bahawalpur, Muhammad Arsalan, Govt. Degree College, Hujra Shah Muqeem, Okara, Pakistan, 2012

2. Performance Appraisal Systems in Higher Education, An Exploration of Christian Institutions, Forrest W. Flaniken, 2009.

3. Performance management of academic staff in south African higher education, M.L.E Mapsela\& Francois Strydom, OCED.

4. STAFF APPRAISAL SYSTEMS AND TEACHER PERFORMANCE AT AGA KHAN SCHOOLS IN KAMPALA DISTRICT.

5. Staff Appraisal Systems and Teacher Performance at Aga Khan Schools in Kampala District, Juliet Namuddu, Education of Makerere University, Uganda, 2010. 